\title{
Enhancing Charge Transfer Efficiency in Graphene Quantum Dots Coupled with Tetrathiafulvalenes
}

Received 00th January 20xx, Accepted 00th January 20xx

DOI: $10.1039 / \times 0 x \times 00000 x$

\author{
Tobias Scharl, ${ }^{\mathrm{c}}$ Andrés Ferrer-Ruiz, ${ }^{\mathrm{a}}$ Adrián Saura-Sanmartín, ${ }^{\mathrm{a}}$ Laura-Rodríguez-Pérez, ${ }^{\mathrm{a}} \mathrm{M}$. Ángeles \\ Herranz, ${ }^{*^{\mathrm{a}}}$ Nazario Martín, ${ }^{\mathrm{ab}}$ Dirk M. Guldi* ${ }^{\mathrm{c}}$
}

www.rsc.org/

Water soluble fluorescent graphene quantum dots have been successfully prepared through a top down approach, that is, starting with graphite, and covalently functionalized with $\pi$ extended tetrathiafulvalene. Charge transfer investigations reveal a noticeably slower charge recombination when compared with exTTF nanoconjugates featuring carbon nanodots, for which a larger presence of trap states is observed.

Photoluminescent carbon nanomaterials, carbon nanodots (CND), and graphene quantum dots (GQD), have triggered an increasing attention over the last decade owing to their lowcost production methods, good photostability, low toxicity and chemical inertness. ${ }^{1} \quad$ These nanocarbons are versatile nanotools for a wide range of applications including novel energy conversion and storage schemes or photocatalytic fuel production systems. $^{2}$

The structures of CND and GQD are quite different and so are their properties, even when both terms have been loosely used and interchanged in many different ways. ${ }^{3}$ CND are mainly prepared by bottom-up synthetic strategies and are best described as amorphous, quasi-spherical nanoparticles that have molecular-like excited states and consequently do not display quantum confinement effects. ${ }^{4}$ On the contrary, GQD are typically obtained from graphene or graphite by topdown approaches and consist of small fragments of few-layer graphene sheets, which leads to two-dimensional disc-shaped structures. ${ }^{5}$

The versatility of CND in charge-transfer assays has been investigated at several occasions. Importantly, the complex electronic structure of CND allows them to act as electron donors or acceptors. ${ }^{6}$ For example, when assembled with perylenediimides $(\mathrm{PDI})^{7}$ or single-walled carbon nanotubes (SWCNT), ${ }^{8}$ CND seem to donate electrons upon photoexcitation. In stark contrast, when combined with

\footnotetext{
Department of Organic Chemistry, Faculty of Chemistry, Complutense University of Madrid, Avda. Complutense s/n, Ciudad Universitaria, E-28040 Madrid, Spain. E-mail: maherran@ucm.es, nazmar@ucm.es

IMDEA-Nanociencia, c/Faraday 9, Campus Cantoblanco, 28049 Madrid, Spain Department of Chemistry and Pharmacy \& Interdisciplinary Center for Molecular Materials (ICMM), Friedrich-Alexander Universität Erlangen-Nürberg, Egerlandstr. 3, 91058 Erlangen, Germany. E-mail: dirk.guldi@fau.de

+ Electronic Supplementary Information (ESI) available: Materials and methods, synthetic details and characterization, Figures S1-S6. See DOI: 10.1039/x0xx00000x
}

porphyrin $^{9}$ or tetrathiafulvalene ${ }^{10}$ derivatives, the CND behave as electron-acceptors. Furthermore, the different composition of CND, and the chemical linkage between CND and the aforementioned electroactive units - by means of covalent or non-covalent approaches - has a notable impact on the charge separation and charge recombination dynamics. ${ }^{9}$ In general, in ultrafast processes, visible-light excitation transforms the singlet excited states into short-lived charge-separated states, which decay between tens and hundreds of ps.

GQD have received much less attention in electron donoracceptor systems. Reported examples of functionalized GQD have mainly considered the improvement of their emission, ${ }^{11}$ the development of composite ${ }^{12}$ or chiral materials, ${ }^{13}$ and the preparation of self-assembled nanomaterials ${ }^{14}$ or supramolecular polymers. ${ }^{15}$

Herein, we decided to explore the synthesis of electron-donor acceptor systems based on GQD and the electron donating $\pi$ extended tetrathiafulvalene units (exTTF). ${ }^{16}$ Following our previous work on covalently linked CND-exTTF nanoconjugates, ${ }^{10}$ we focused in the preparation of GQDexTTF analogous, to investigate the structural differences between CND and GQD nanomaterials and how their differences might influence the charge-transfer dynamics in excited state events.

The production of GQD has been carried out from graphene oxide (GO) obtained by the Kovtyukhova-Hummer's method ${ }^{17}$ and subsequent oxidative cutting in a mixture of concentrated $\mathrm{H}_{2} \mathrm{SO}_{4} / \mathrm{HNO}_{3}$, followed by neutralization of the excess of acid, and dialysis similar to that reported by Haino. ${ }^{11}$ First insights in the morphology of the as-prepared GQD were obtained from transmission electron microscopy (TEM) and atomic force microscopy measurements (AFM). Here we were able to confirm the presence of a mixture of isolated and few-layered GQD with sizes in the range from 4 to $18 \mathrm{~nm}$ and $1.3 \pm 0.3 \mathrm{~nm}$ heights (Fig. S1). With the aim of obtaining additional structural information, Fourier transform infrared (FTIR) and Raman spectroscopies were performed. In the FTIR, the stretching vibrations of the $\mathrm{OH}, \mathrm{C}=\mathrm{O}$ and $\mathrm{C}-\mathrm{O}$ bonds were found at 3450, 1719 and $1382-1103 \mathrm{~cm}^{-1}$, in addition to the skeletal in-plane vibration of the $\mathrm{C}=\mathrm{C}$ bonds at $1611 \mathrm{~cm}^{-1}$. The latter confirms that GQD retain the $s p^{2}$ lattice of pristine graphite (Fig. 1). Furthermore, the Raman spectrum shows the 
characteristic G-band at $1600 \mathrm{~cm}^{-1}$ related to the vibration of the $s p^{2}$ carbons backbone and also an intense D-band at 1390 $\mathrm{cm}^{-1}$. Considering $a \mathrm{I}_{\mathrm{D}} / \mathrm{I}_{\mathrm{G}}$ ratio of 0.92 we infer the success in oxidative cutting and introduction of $s p^{3}$-defects in GQD structure (Fig. S2).

In the next step, we activated the carboxylic acids, which are present in GQD, via acid chloride formation and subsequent esterification reaction with 2-hydroxymethyl-exTTF ${ }^{18}$ to yield the GQD-exTTF nanoconjugates (Scheme 1).

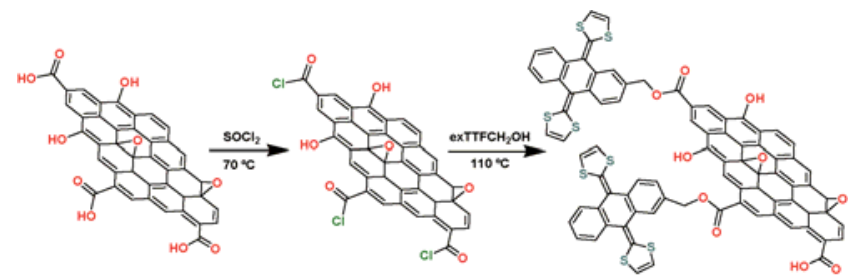

Scheme 1 Schematic representation of the GQD-exTTF synthesis.

AFM measurements provided information about the sizes and dimensions of the GQD-exTTF nanoconjugates. Overall, the images revealed roundish morphologies with average sizes of $4.6 \pm 1.6 \mathrm{~nm}$, which are higher than those seen in the asprepared GQD, although several agglomerated morphologies are observed (Fig. 1). No significant changes after the functionalization were observed in the GQD core by Raman spectroscopy, where the characteristic D- and G-bands are observed, or by XRD, which presents a typical amorphous graphitic pattern (Fig. S3).
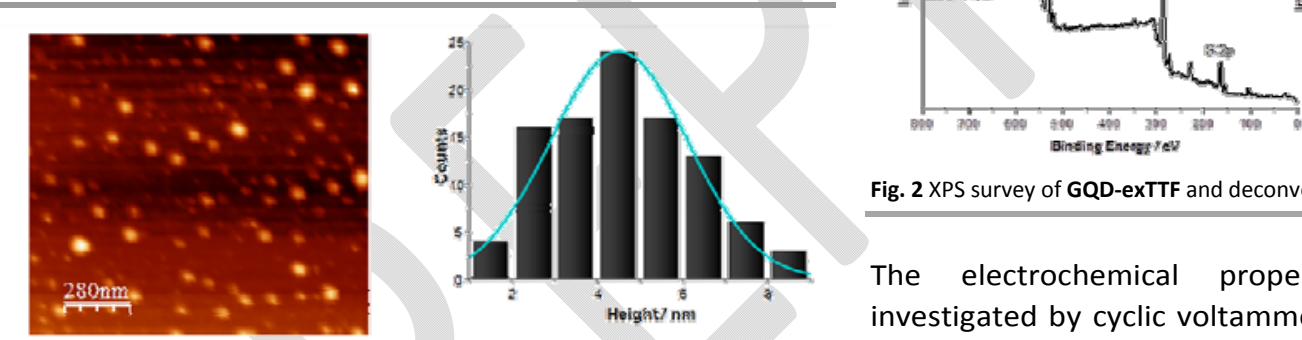

assigned to the thermal cleavage of the exTTF. In addition, FTIR spectroscopy offers evidence for the new functional groups, which were introduced on GQD. The C-S stretching vibrations were noted at $645 \mathrm{~cm}^{-1}$ with albeit lower intensity. Moreover, it is worth to point out the presence of the $\mathrm{C}=\mathrm{O}$ stretching vibration at $1740 \mathrm{~cm}^{-1}$ as part of the newly formed ester groups.

X-ray photoelectron spectroscopy (XPS) was valuable to gain structural information about GQD-exTTF. XPS survey spectrum reveals the presence of oxygen, carbon, and, more interestingly, sulphur at 531.6, 284.6, and $163.6 \mathrm{eV}$, respectively (Fig. 2). The $\mathrm{C} 1 \mathrm{~s}$ band was deconvoluted using six components. To this end, a major component at $284.1 \mathrm{eV}$ due to $\mathrm{C}=\mathrm{C} / \mathrm{C}-\mathrm{C}$ bonds is complemented by four minor components at higher binding energies stemming from carbon atoms bound to oxygen in different configurations: $284.8 \mathrm{eV}$ (C-O), $285.7 \mathrm{eV}(\mathrm{C}-\mathrm{O}-\mathrm{C}), 286.2 \mathrm{eV}(\mathrm{C}=\mathrm{O})$ and $287.9 \mathrm{eV}(\mathrm{O}-\mathrm{C}=\mathrm{O})$. The last component at about $291.0 \mathrm{eV}$ corresponds to $\pi-\pi^{*}$ bonds. ${ }^{19}$ The XPS S 2p band measured at $163.6 \mathrm{eV}$ is characteristic for C-S-C in tetrathiafulvalene (TTF) derivatives. ${ }^{20}$ The distinctive absorptions of exTTF were evident in the absorption spectrum of GQD-exTTF, as two maxima at 367 and $432 \mathrm{~nm}$ (Fig. S5).
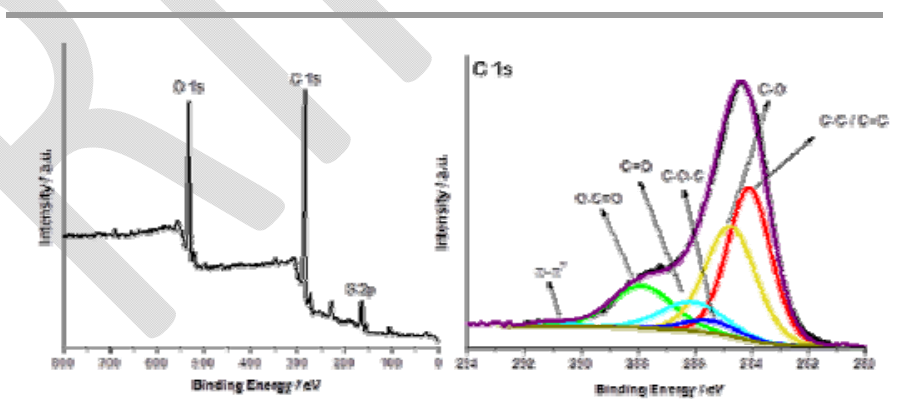

Fig. 2 XPS survey of GQD-exTTF and deconvoluted C 1s spectrum.

The electrochemical properties of GQD-exTTF were investigated by cyclic voltammetry (CV) in saturated solutions of DMSO containing $0.1 \mathrm{M} \mathrm{nBu}_{4} \mathrm{PF}_{6}$ in an argon atmosphere. The CV (Fig. S4) displays the characteristic single two-electron and chemically reversible oxidation of exTTF at $+0.01 \mathrm{~V} v s$. $\mathrm{Ag} / \mathrm{AgNO}_{3}$. Analogous results were obtained in $\mathrm{CV}$ analyses of an exTTF reference and CND-exTTF conjugates. ${ }^{10}$

Following the ground state characterization of GQD-exTTF the excited state features of GQD-exTTF were explored. Fluorescence spectroscopy reveals a nearly quantitative quenching of the GQD emission after their covalent funtionalization with exTTF units (Fig. S6). In order to prove the existence of a charge transfer process behind this quenching, transient absorption spectroscopic measurements with GQD-exTTF have been carried out. Excitation at $387 \mathrm{~nm}$ leads to the formation of an exTTF centered excited state with an absorption minimum at $440 \mathrm{~nm}$ and absorption maxima at 474,610 , and $710 \mathrm{~nm}$. In contrast, to the exTTF and GQD references, this transient converts into a new transient within two picoseconds. This new transient is characterized by transient maxima at $467,546,610$, and $674 \mathrm{~nm}$ as well as a distinct $440 \mathrm{~nm}$ transient minimum, which are in sound 
agreement with pulse radiolytic findings regarding the oxidation of exTTF. ${ }^{18,21-22}$ In other words, charge separation, in which exTTF are one-electron oxidized and GQD are oneelectron reduced, evolves upon formation of the initial excited state. Finally, the charge separated state recombines to the ground state on a timescale of tens of picoseconds. To gain deeper insights into the excited state dynamics, we conducted multi wavelength analyses. In Fig. 3 the species associated spectra (SAS) and the corresponding concentration profiles are shown. The spectral features of the SASs are in accordance with the proposed kinetic model, that is, an exTTF based excited state (SAS1) with a lifetime of $2.0 \mathrm{ps}$ and a GQD"exTTF $^{*+}$ charge separated state (SAS2) with a lifetime of 54 ps. Notable is the lifetime of the GQD ${ }^{\circ-}$-exTTF ${ }^{\circ+}$ charge separated state (SAS2), which is appreciable longer than that determined in the corresponding CND conjugates. ${ }^{10}$ The less amorphous character of GQD compared to CND is likely to facilitate a better delocalization of the electrons along the carbon network.
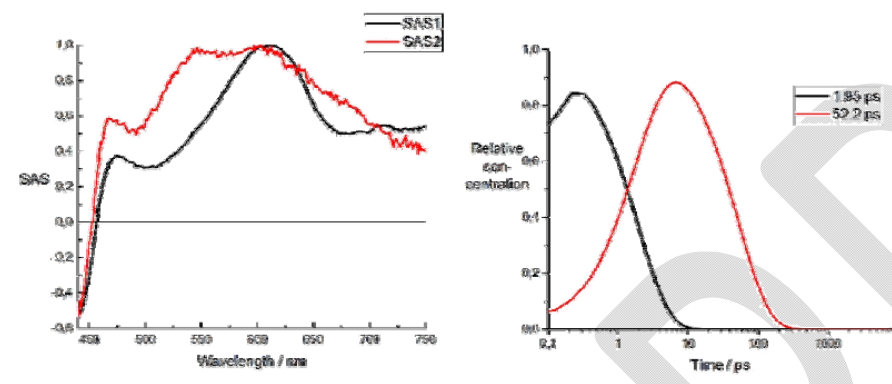

Fig. 3 Top: Normalized species associated transient absorption spectra (SAS1 and SAS2) for GQD-exTTF obtained at 22 으 in DMSO. Bottom: corresponding concentration profiles.

In conclusion, we have synthesized GQD-exTTF electron-donor acceptor nanoconjugates through the reaction of edgeoxidized GQD, obtained from graphite, with 2-hydroxymethylexTTF. Analyses by means of AFM, TGA, FTIR, Raman, XRD, and absorption underlined the graphitic nature of the GQD core and confirmed the covalent bonding of exTTF to GQD. When considering excited-state interactions, a prominent quenching of the yellowish emission of GQD is noticed as consequence of a charge separation, which was confirmed by transient absorption measurements. Remarkably, chargerecombination in GQD-exTTF (54 ps) is slower than in CNDexTTF (13 ps), ${ }^{10}$ a fact related with the different structure of GQD and CND. These results appear particularly promising in light of further developments in GQD-based electron-donor acceptor systems as new and promising materials for solarenergy conversion applications.

Financial support from the European Research Council (ERC320441-Chirallcarbol), the Ministerio de Economía y Competitividad (MINECO) of Spain (Projects CTQ2017-83531-R and CTQ2017-84327-P), and the Community of Madrid (PHOTOCARBON project S2013/MIT-2841) is acknowledged. This work was also funded by the Deutsche
Forschungsgemeinschaft (DFG) via SFB 953 "Synthetic Carbon Allotropes".

\section{Conflicts of interest}

There are no conflicts to declare.

\section{Notes and references}

1 L. Xiao and H. Sun, Nanoscale Horiz., 2018, 3, 565.

2 G. A. M. Hutton, B. C. M. Martindale and E. Reisner, Chem. Soc. Rev., 2017, 46, 6111.

3 A. Cayuela, M. L. Soriano, C. Carrillo-Carrión and M. Valcárcel, Chem. Commun., 2016, 52, 1311.

4 (a) J. B. Essner, J. A. Kist, L. Polo-Parada and G. A. Baker, Chem. Mater., 2018, 30, 1878; (b) F. Rigodanza, L. Đorđević, F. Arcudi and M. Prato, Angew. Chem. Int. Ed., 2018, 57, 5062; (c) S. Lu, G. Xiao, L. Sui, T. Feng, X. Yong, S. Zhu, B. Li, Z. Liu, B. Zou, M. Jin, J. S. Tse, H. Yan and B. Yang, Angew. Chem. Int. Ed., 2017, 56, 6187.

5 (a) S. Zhao, J. Lavie, L. Rondin, L. Orcin-Chaix, C. Diederichs, P. Roussignol, Y. Chassagneux, C. Voisin, K. Müllen, A. Narita, S. Campidelli and J.-S. Lauret, Nat. Commun., 2018, 9, 3470; (b) R. Sekiya, Y. Uemura, H. Naito, K. Naka and T. Haino, Chem. Eur. J., 2016, 22, 8198; (c) D. B. Shinde and V. K. Pillai, Angew. Chem. Int. Ed., 2013, 52, 2482.

6 L. Vallan, R. Canton-Vitoria, H. B. Gobeze, Y. Jang, R. Arenal, A. M. Benito, W. K. Maser, F. D'Souza and N. Tagmatarchis, J. Am. Chem. Soc., 2018, 140, 13488.

7 V. Strauss, J. T. Margraf, K. Dirian, Z. Syrgiannis, M. Prato, C. Wessendorf, A. Hirsch, T. Clark and D. M. Guldi, Angew. Chem. Int. Ed., 2015, 54, 8292.

8 V. Strauss, J. T. Margraf, T. Clark and D. M. Guldi, Chem. Sci., 2015, 6, 6878.

9 (a) T. Scharl, A. Cadranel, P. Haines, V. Strauss, S. Bernhardt, S. Vela, C. Atienza, F. Gröhn, N. Martín and D. M. Guldi, Chem. Commun., 2018, 54, 11642; (b) A. Cadranel, V. Strauss, J. T. Margraf, K. A. Winterfeld, C. Vogl, L. Đorđević, F. Arcudi, H. Hoelzel, N. Jux, M. Prato and D. M. Guldi, J. Am. Chem. Soc., 2018, 140, 904; (c) F. Arcudi, V. Strauss, L. Dordevic, A. Cadranel, D. M. Guldi and M. Prato, Angew. Chem. Int. Ed., 2017, 56, 12097.

10 A. Ferrer-Ruiz, T. Scharl, P. Haines, L. Rodríguez-Pérez, A. Cadranel, M. A. Herranz, D. M. Guldi and N. Martín, Angew. Chem. Int. Ed., 2018, 57, 1001.

11 R. Sekiya, Y. Uemura, H. Murakami and T. Haino, Angew. Chem. Int. Ed., 2014, 53, 5619.

12 R. Ye, Z. Peng, A. Metzger, J. Lin, J. A. Mann, K. Huang, C. Xiang, X. Fan, E. L. G. Samuel, L. B. Alemany, A. A. Martí and J. M. Tour, ACS Appl. Mater. Interfaces, 2015, 7, 7041.

13 (a) M. Vázquez-Nakagawa, L. Rodríguez-Pérez, M. A. Herranz and N. Martín, Chem. Commun., 2016, 52, 665; (b) N. Suzuki, Y. Wang, P. Elvati, Z.-B. Qu, K. Kim, S. Jiang, E. Baumeister, J. Lee, B. Yeom, J. H. Bahng, J. Lee, A. Violi and N. A. Kotov ACS Nano, 2016, 10, 1744.

14 N. Maity, P. Chakraborty and A. K. Nandi, Langmuir, 2017, 33, 13384.

15 Y. Uemura, K. Yamato, R. Sekiya and T. Haino, Angew. Chem. Int. Ed., 2018, 57, 4960.

16 F. G. Brunetti, J. L. López, C. Atienza and N. Martín, J. Mater. Chem., 2012, 22, 4188.

17 N. I. Kovtyukhova, P. J. Ollivier, B. R. Martin, T. E. Mallouk, S. A. Chizhik, E. V. Buzaneva and A. D. Gorchinskiy, Chem. Mater., 1999, 11, 771. 
18 M. A. Herranz, C. Ehli, S. Campidelli, M. Gutiérrez, G. L. Hug, K. Ohkubo, S. Fukuzumi, M. Prato, N. Martín and D. M. Guldi, J. Am. Chem. Soc., 2008, 130, 66.

19 G. Neri, A. Scala, E. Fazio, P. G. Mineo, A. Rescifina, A. Piperno and G. Grassi, Chem. Sci., 2015, 6, 6961.

20 (a) D. Choudhury, B. Das, D. D. Sarma and C. N. R. Rao, Chem. Phys. Lett., 2010, 497, 66; (b) J. Mateos-Gil, L. RodríguezPérez, M. Moreno Oliva, G. Katsukis, C. Romero-Nieto, M. A Herranz, D. M. Guldi and N. Martín, Nanoscale, 2015, 7, 1193.
21 (a) D. M. Guldi, L. Sánchez and N. Martín, J. Phys. Chem. B, 2001, 105, 7139; (b) M. A. Herranz, N. Martín, S. Campidelli, M. Prato, G. Brehm, D.M. Guldi, Angew. Chem. Int. Ed., 2006, 45, 4478; (c) S. S. Gayathri, M. Wielopolski, E. M. Pérez, G. Fernández, L. Sánchez, R. Viruela, E. Ortí, D. M. Guldi and N. Martín, Angew. Chem. Int. Ed., 2009, 48, 815.

22 V. Strauss, A. Roth, M. Sekita and D M. Guldi, Chem, 2016, 1, 531.

\section{Table of contents entry}

Electron transfer investigations with graphene quantum dots reveal a slower charge recombination than with carbon nanodots in tetrathiafulvalene nanoconjugates

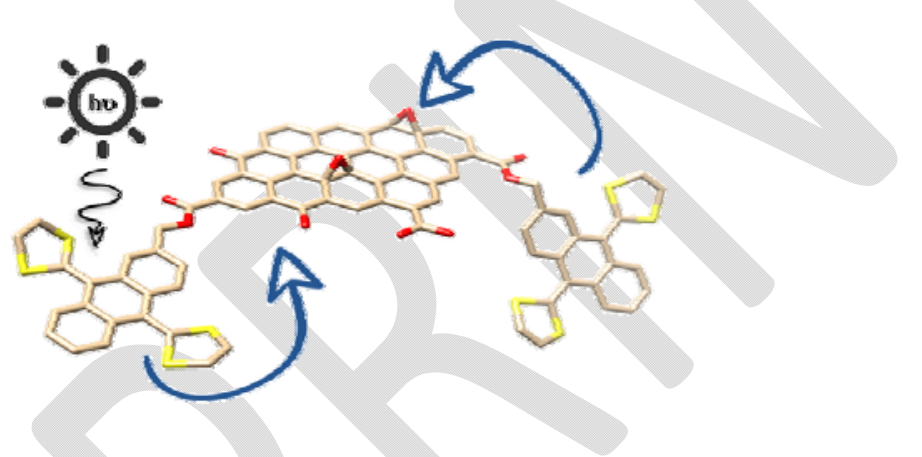

